\title{
Fatal ventricular fibrillation after treatment with digoxin in a 27-year-old man with mitral leaflet prolapse syndrome
}

\author{
P I SALMELA, M IKÄHEIMO, H JUUSTILA \\ From the Department of Medicine, University Central Hospital, Oulu, Finland
}

SUMMARY A 27-year-old man with typical mitral leaflet prolapse syndrome was under medical care for eight years with ventricular arrhythmias resistant to various antiarrhythmic drugs. He was started on digoxin, $0.25 \mathrm{mg}$ daily, because of echocardiographically demonstrated left ventricular dilatation and functional impairment: he died of ventricular fibrillation 15 days later.

The prognosis of the mitral leaflet prolapse syndrome, which is among the commonest of cardiac abnormalities, is generally good, ${ }^{1}$ though a few sudden deaths, probably caused by ventricular arrhythmias, have been reported. ${ }^{2}$ We report a patient who was under observation for eight years and who died of ventricular fibrillation 15 days after starting treatment with digoxin.

\section{Case report}

A male engineer, previously under medical care for three years because of a systolic murmur and ventricular extrasystoles at rest, was admitted to hospital at the age of 23 after a syncopal episode. Initial electrocardiogram monitoring showed bigeminal ventricular extrasystoles, which did not respond to lignocaine infusion, beta-blocking agents, procainamide, or phenytoin. He was not dyspnoeic or febrile and there was no tachycardia, gallop rhythm, pericardial friction rub, or raised jugular venous pressure. Radiologically, slight cardiac enlargement was evident. The 12 lead electrocardiogram was normal apart from wide QRS ectopics. On subsequent treatment with propranolol $20 \mathrm{mg}$ three times daily, the patient continued to experience palpitation and sensations of dizziness, but no further syncope. During the next three years quinidine alone or in combination with betablocking agents failed to abolish the extrasystoles, and eventually no further treatment was given.

At the age of 26 the patient was examined for the first time at Oulu University Centre. A mid-systolic click and late systolic murmur of mitral regurgita- tion, both uninfluenced by postural manoeuvres, were heard over the cardiac apex. The resting 12 lead electrocardiogram showed negative $T$ waves in leads III and aVF, and low QRS voltages in the standard leads. The chest $x$-ray film was normal. Echocardiography showed end-systolic mitral leaflet prolapse and a suspicion of thickening of the mitral leaflets (Fig. 1). The echocardiographic left ventricular end-diastolic diameter was $60 \mathrm{~mm}$, and ejection fraction 73 per cent. Though the patient continued to experience palpitation, no treatment was given.

At a follow-up examination one year later the left ventricular end-diastolic dimension was $66 \mathrm{~mm}$, and the ejection fraction 54 per cent. The resting 12 lead electrocardiogram showed low voltages, negative $T$ waves in leads III and a VF, and $U$ waves in leads $I$ and aVL. The $P Q$ and $Q T c$ intervals were normal. In view of the left ventricular dilatation and reduced ejection fraction noted in the echocardiogram, treatment was started with digoxin, $0.25 \mathrm{mg}$ daily. Fifteen days later, while at home watching television, he suddenly lost consciousness and became pulseless. Resuscitative efforts, started by relatives, were continued in the hospital for three and half hours without success. Electrocardiographic monitoring upon admission showed ventricular fibrillation and this proved resistant to lignocaine, procainamide, and DC countershock.

At necropsy left ventricular hypertrophy was found, the myocardium measuring $2 \mathrm{~cm}$ at maximum thickness. The posterior leaflet of the mitral valve was thick, floppy, and bag-shaped. The other 
valves were normal. The gross anatomy of the coronary arteries was normal and nothing suggesting myocardial infarction was noted. Histologically (Fig. 2), the mitral leaflet showed abundant deposition of material which was Alcian Blue positive, diastase resistant, and PAS positive, characteristic of myxomatous degeneration.

\section{Discussion}

"The prognosis of the patient with mitral leaflet prolapse syndrome largely depends on whether there is an underlying cause or associated condition." 1 Despite the high prevalence of arrhythmias in the syndrome, only a few sudden deaths, possibly caused by ventricular fibrillation, have been reported. ${ }^{2}{ }^{3}$ The pathogenesis of the ventricular arrhythmias is not understood. ${ }^{4}$ There are suggestions that ventricular ectopy is independent of valve dysfunction and operates on the basis of a primary myocardial disorder. ${ }^{15}$ In the present case underlying or associated cardiomyopathy is perhaps

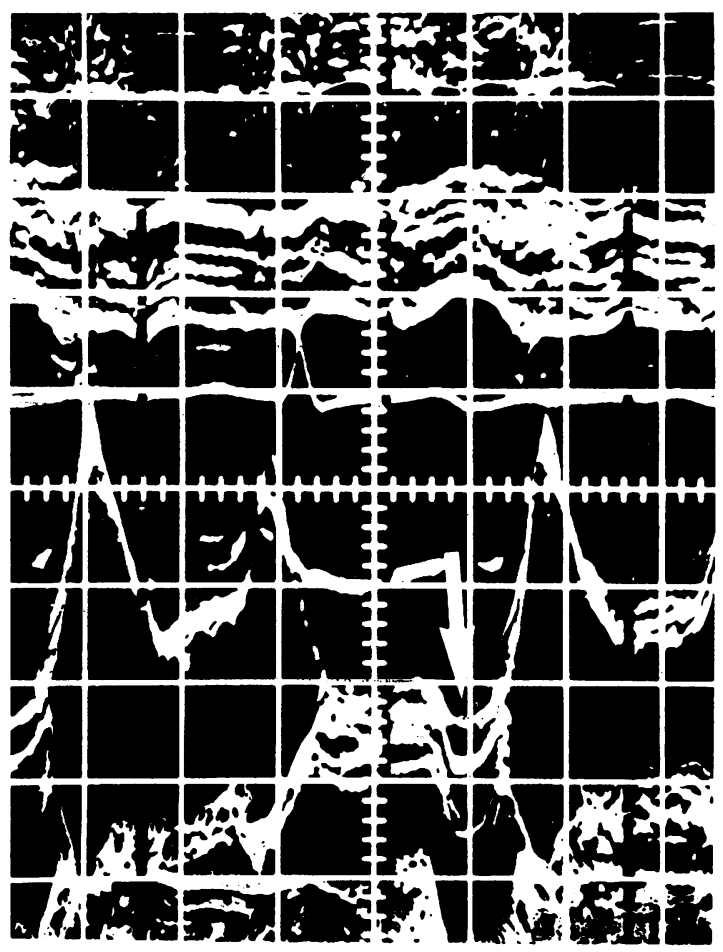

Fig. 1 M-mode echocardiogram from the mitral valve showing the late systolic mitral prolapse (arrow). Note also the slightly thickened posterior mitral leaflet (in diastole) indicating possible myxomatous infiltration. suggested by the finding of left ventricular wall thickening. On the other hand, ventricular arrhythmias could arise from stretching of the valve leaflet tissue with augmented myocardial pacemaker activity by a mechanical stimulus effect or by ischaemia from increased papillary muscle tension. ${ }^{6}$ These mechanisms could also alter ventricular refractory properties or conduction and possibly lead to ventricular re-entry. ${ }^{7}$ In some cases of mitral leaflet prolapse syndrome accessory conduction pathways exist as in the Wolff-Parkinson-White syndrome, even though there may not be any evidence on the surface electrocardiogram. ${ }^{89}$ Treatment of ventricular arrhythmias in symptomatic patients, particularly if the resting electrocardiogram shows inferoposterior ST segment and $T$ wave changes, ${ }^{10}$ is recommended with beta-adrenergic blocking agents, ${ }^{11}$ though these are not always effective. ${ }^{1}$

Digitalis has been used previously, ${ }^{12}{ }^{13}$ and there has been no claim that it had any connection with the fatal outcome in the reported cases of sudden death, though caution has been urged in respect of the use of this drug in these patients. ${ }^{9}$

The liability to arrhythmias caused by digitalis toxicity has been found to be increased in some cardiac diseases such as myocardial infarction and in certain cardiomyopathies. ${ }^{14}$ Arrhythmias produced by digitalis are the results of alterations in impulse formation or conduction or both. ${ }^{15}$ Ventricular ectopic activity is increased by bringing the phase IV resting potential closer to the threshold potential. In the mitral leaflet prolapse syndrome ventricular automatism could be further enhanced by alteration in pacemaker activity, caused by the inotropic action of digitalis with stretching of the papillary muscle. On the other hand, in view of the possibility of accessory conduction pathways, ${ }^{9}$ digitalis glycosides could be hazardous in certain re-entry phenomena by reducing the effective refractory period. ${ }^{7816}$ In the present case, the relatives were unable to give any history suggestive of digitalis intoxication, and the serum digoxin concentration was not assayed. Moreover, no factors predisposing to electrolyte disturbances were apparent. Objective evidence of the WolffParkinson-White syndrome and supraventricular arrhythmias is lacking, so that we cannot reach any conclusion concerning the mechanism of the fatal episode of ventricular fibrillation in our case. The timing of events does, however, suggest an association between digoxin treatment and the fatal event.

This case raises the possibility that starting treatment with digoxin in patients with mitral leaflet prolapse, abnormalities of the resting electro- 


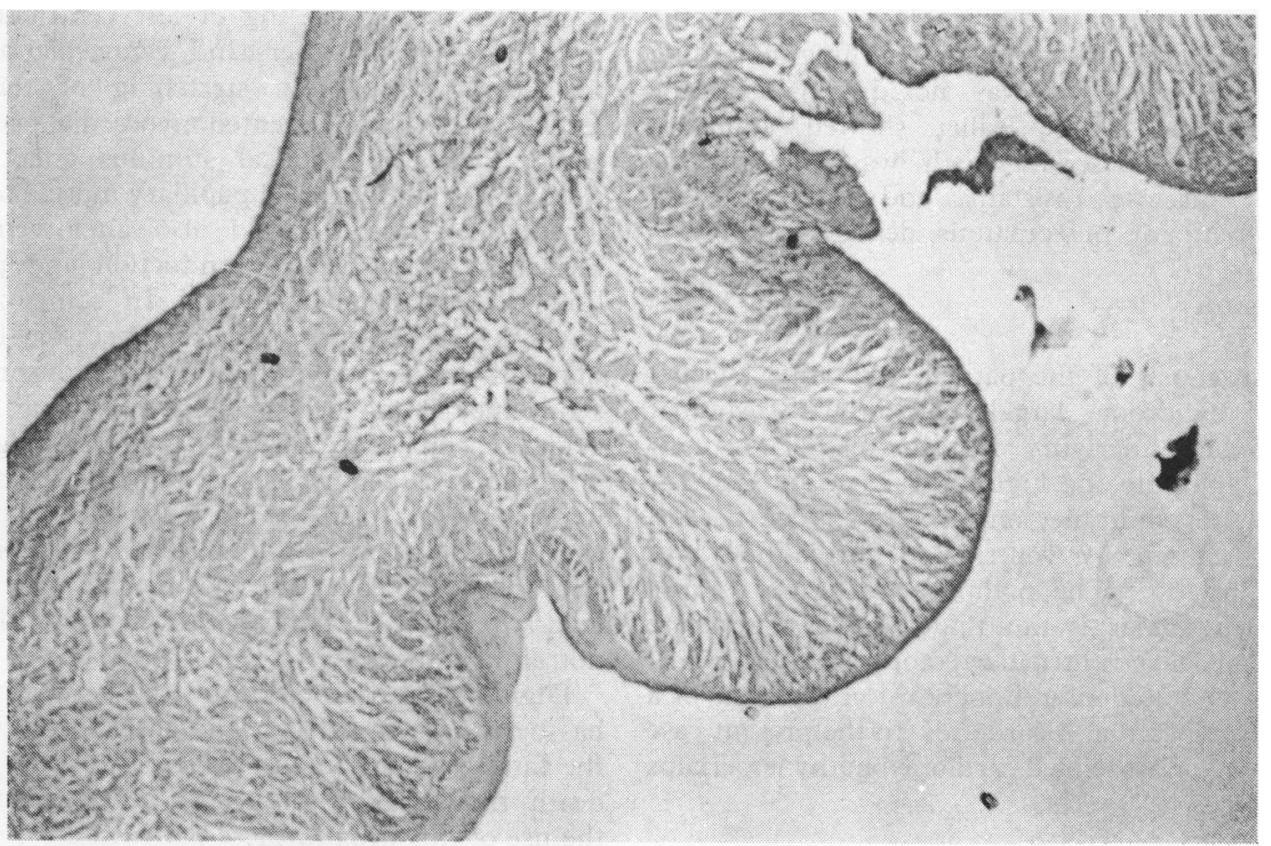

Fig. 2 This figure shows extensive deposition of myxomatous material within the fibres of the posterior leaflet of the mitral valve. The atrial surface is at top left. (Alcian Blue stain at $p H 2.5$. Original magnification $\times 33$.)

cardiogram, and ventricular ectopic activity may result in ventricular fibrillation. This possibility should be considered and it should be the subject of further study.

\section{References}

1 Barlow JB, Pocock WA. Mitral valve prolapse, the specific billowing mitral leaflet syndrome, or an insignificant nonejection systolic click. Am Heart $\mathcal{f}$ 1979; 97: 277-85.

2 Jeresaty RM. Sudden death in the mitral valve prolapse-click syndrome. Am $\mathcal{f}$ Cardiol 1976; 37: 317-8.

3 Shappell SD, Marshall CE, Brown RE, Bruce TA. Sudden death and the familial occurrence of midsystolic click, late systolic murmur syndrome. Circulation 1973; 48: 1128-34.

4 Swartz $\mathrm{MH}$, Teichholz LE, Donoso E. Mitral valve prolapse, a review of associated arrhythmias. $A m \mathfrak{F}$ Med 1977; 62: 377-89.

5 Scampardonis G, Yang SS, Maranhão V, Goldberg $H$, Gooch AS. Left ventricular abnormalities in prolapsed mitral leaflet syndrome. Circulation 1973; 48: 287-97.
6 Wit AL, Fenoglio JJ Jr, Hordof AJ, Reemtsma K. Ultrastructure and transmembrane potentials of cardiac muscle in the human anterior mitral valve leaflet. Circulation 1979; 59: 1284-92.

7 Engel TR, Meister SG, Frankl WS. Ventricular extrastimulation in the mitral valve prolapse syndrome. Evidence for ventricular re-entry. $\mathcal{F}$ Electrocardiol 1978; 11: 137-42.

8 Chandraratna PAN, Ribas-Meneclier C, Littman $B B$, Samet $P$. Conduction disturbances in patients with mitral valve prolapse. $\mathcal{F}$ Electrocardiol $1977 ; 10$ : 233-6.

9 Josephson ME, Horowitz LN, Kastor JA. Paroxysmal supraventricular tachycardia in patients with mitral valve prolapse. Circulation 1978; 57: 111-5.

10 Campbell RWF, Godman MG, Fiddler GI, Marquis RM, Julian DG. Ventricular arrhythmias in syndrome of balloon deformity of mitral valve. Definition of possible high risk group. Br Heart $\mathcal{f} 1976$; 38: 1053-7.

11 Winkle RA, Lopes MG, Goodman DJ, Fitzgerald JW, Schroeder JS, Harrison DC. Propranolol for patients with mitral valve prolapse. Am Heart $\mathcal{f}$ 1977; 93: 422-7.

12 Hancock EW, Cohn $\mathrm{K}$. The syndrome associated with midsystolic click and late systolic murmur. Am f Med 1966; 41: 183-96.

13 Gooch AS, Vicencio F, Maranhao V, Goldberg H. Arrhythmias and left ventricular asynergy in the 
prolapsing mitral leaflet syndrome. Am $\mathcal{F}$ Cardiol 1972; 29: 611-20.

14 Mason DT, DeMaria AN, Amsterdam EA, et al. Antiarrhythmic agents: mechanisms of action, clinical pharmacology and therapeutic considerations. In Avery GS, ed. Cardiovascular drugs, vol 1: Antiarrhythmic, antihypertensive and lipid lowering drugs. New York, Sydney, Auckland: ADIS Press, 1977: 75-133.

15 Doherty JE, Kane JJ. Clinical pharmacology and therapeutic use of digitalis glycosides. In Avery GS, ed. Cardiovascular drugs, vol 1: Antiarrhythmic, antihypertensive and lipid lowering drugs. New York, Sydney, Auckland: ADIS Press, 1977: 134-72.

16 Zipes DP, Foster PR, Troup PJ, Pedersen DH. Atrial induction of ventricular tachycardia: reentry versus triggered automaticity. Am $\mathcal{f}$ Cardiol $1979 ; 44: 1-8$.

Requests for reprints to Dr P I Salmela, Department of Medicine, University Central Hospital, SF-90220 Oulu 22, Finland. 